\title{
A Study on the Origin of Ancient Chinese Private Garden Bridges
}

\author{
Yang Li \\ Art Institute of Suzhou University, 215123, China
}

Keywords: private gardens, Bridges, garden bridge.

\begin{abstract}
In the garden bridge magnificent imperial gardens, private garden is different from it is have fun in the illicit close space. Here not only with the echo of the surrounding buildings, garden bridge is different from the surrounding buildings highlight its delicate lasting appeal however. In order to study the evolution of the modern garden bridge in construction process, you need to do some in-depth study of the origin of the garden bridge.
\end{abstract}

\section{Introduction}

Is based on Chinese garden is a natural landscape, garden will make up a significant proportion of water, and organization associated with the water landscape, mostly related to the layout of the bridge, the bridge is of garden in industrial buildings. "The garden cure," yue "tendril tong jin, yuan to fly beam can be", "Embodied the original" park said "[one phase] four, country to fly" tendril tong jin, yuan liang can "[two legislative]" if... hydrophobic endless, breaks through bridge "(Ming) into the Chen Zhi annotations, embodied the notes, China building industry press, in May 1988.... if a hydrophobic endless, breaks through bridge ". Said, is the beauty of garden Bridges hidden source.....

\section{In The Early Qin Period}

Back we have to find garden bridge landscape history sy sternberg, from the book of songs can be seen in the account of, as early as when king wen of zhou with construction activities today, says the spirit form. (about the 11th century BC) (because of "bridge" in the beginning of the han dynasty Bridges is inspired by fallen tree across the river to build a wooden bridge, wooden bridge, only "beam" word, the pre-qin period through the history of the ancient bridge in our country, the shells to the development of the western zhou period, was the preliminary development period of bridge construction in our country, the bridge built during this period, are freely with wood as the main building materials, and more as the bridge and wooden bridge, and the suspension bridge on the moat) see tang whistling arrow, zhen-yu huang, Pan Xiaolan compiled, the ancient Chinese architecture and landscape, tourism education press, August 2003. the book of songs, jedaiah, gv 10 articles have spirit form of management, as well as the description of the form. Such as "king in spirit form, deer deer togeher volts.

Deer deer bare, white horse pole pole. Wang fen in spirit, Yu Ren diving." This will appear in the form of spirit is not only the natural scenery, and build artificial facilities such as digging marsh, so water can bridge. (only the bridge also cannot be called a "bridge" and freely with wood as the main building materials) of this we can infer if the spirit in the form of a bridge has great potential to bridge, and the account of "form", jinwen pictographic meaning in planting trees for fruits and vegetables like a natural ecological landscape. For the ancient imperial aristocracy hunting, amusement of a form of garden. Birds and animals natural breeding ground for breeding, in the form of vegetation is given priority to with natural scenery to tame beasts for enjoying the buildings and grounds, has said the beast.

Similar today construction also see tang dynasty Liu Guangwei contained in the "to" Wu Wangshou dream "summer driving lake", To quote (tang) Liu Guangwei that Cao Lindi collation, "wu", jiangsu ancient books publishing house, 1999. summer shade in the summer of that year, in this "chisel pool lake, pestered him". He lu built cheung chau yuan for safari, is a model of the suzhou 
gardens. At this point on both ends of the bridge is likely to be only the connection pool in the garden of shore traffic function of the "road".

Shiji volume five, Qin Zhaoxiang fifty described in ten years "Quotations from sima qian from han, song pei Yin set, tang SiMaZhen somalia's government, tang zhang feast justice, shiji volume 1, volume 1 to 7. P214, 218, published by zhonghua book company, 1959, the first edition in November 1982, second edition, Beijing in November 1982 eighth printing. Volume five Qin Zhaoxiang fifty "... a river crossing at the beginning of "ten years. Tang zhang feast justice [1] "the bridge in the same state LinJin County east, crossing the river to PuZhou, this pu bridge also today."... at the beginning of a river crossing ". This is documented in the earliest we can consult to the river crossing.

\section{The Qin and Han Dynasties}

After qin shi huang unified China, there is also a landscape construction in the palace construction activities, such as "lead WeiShui for pool, built for loose, ying." Simulation is immortal island, Chinese gardens with gardening technique of artificial piled mountain that began in at this time. Developed on the basis of the han dynasty, in the form of a new form of landscape garden. Distribution of palace architecture, become to buildings as the main body of today [2]. Qin and han dynasties appeared first in the history of Chinese garden landscape. Are the common features of today to present to the Chinese culture as the background, together with the pre-qin thinkers of "of" nature and man as a guide, create a vast, emphasizing everything, layout "as heaven and earth", "the count of Yin and Yang" of time and space art, as a symbol of unity big empire and centralized dynasty, qin and han dynasties today use of penglai mythology system provided by the fairy mountain imagine a sea landscape, established the "three mountain" a pool of landscape system layout. Thus, water, mountains, and construction become legs and three of the Chinese traditional garden landscape elements.

This period in the garden bridge, not only have the major role of link traffic, and also there is divided into the water, as the observation boarding bridge to admire the view and group and architectural landscape scene as the main entourage of foil to create artistic conception and the building form a beautiful picture and some other material [3]. When the western han dynasty has rich nobles of the private garden, the size is smaller than today, the content is still not out of form and garden tradition, in building group combined with the natural landscape, such as Liang Xiaowang Washington it, MAO ling rich Yuan Guanghan under north Mang building garden, construct Shi Weishan, stone mountain which was built with artificial purchase. , in the garden there is a lot of buildings still more extensive garden scenery in general, this type of garden so that being used up to the end of the eastern han dynasty. The eastern han dynasty years, private gardens are also beginning to been recorded [4].

Word "suzhou government record", and "wu table hidden door", have "(clear) Gu Zhentao from anglin by JiaoDian, "wu door table implicit" jiangsu ancient books publishing house, 1999. Ze homes, in jili south, the ancient name Ze, Wu Dafu Ze melt habitation" entry. According to historical records, Ze harmony is the eastern han dynasty DanYangRen, had congregated with xuzhou tao qian, after being built in xuzhou FuTu shrine, to promote the development of Buddhism at that time, played a large role. Although he built home garden in suzhou, due to the long time, and records to neglect inadvertently, has been difficult to have a more detailed understanding, but that in the history of development of suzhou gardens, is the earliest known private garden, has the extremely important historical value. In addition because the iron has been widely used during the warring states period, it create conditions for the stone used in Bridges.

In addition this period of arch structure began to construct the bridge in our country is a big breakthrough in the history of architecture, the emperor Liu Che miyagi JianZhang palaces built the largest, from the original in the guanzhong sites' disposition JianZhang palace in the bird's eye view, we can see that in a size too liquid pool is not small penglai mountain, mount yingzhou arch bridge connection. This arch Bridges have connection traffic landscape points, group scene and dividing the water but the water space interval. in addition, writing unearthed in shandong cangshan county has 
since the oblique ladder out of a stone arch counts, pillar hanging out the image of the waterside pavilion. shandong zaozhuang, zou yellow road, tuen mun, teng county west registered permanent residence, in cangshan county to city unearthed stone, such as some props also add at the bottom of the inclined central stairway to reduce the cantilever length of diagonal member, because hanging out of the building is located on the surface of the water, they can be thought of as belonging to the democratic water garden architecture, and step into the QiaoTi can be regarded as a variant of wood bridge architecture.

This is like "fly pavilion", also known as the pavilion, complex, namely the overpass. Across the channel between the ancient castle in the palace. "Three auxiliary Huang Tu" : "in the house refers to the han central palace west across the city as a flying pavilion JianZhang palace, compose chariot (ni m: n) or more." From the three auxiliary Huang $\mathrm{Tu}$ "school certificate, Chen straight school certificate, volume 2, han palace. The original "emperor in weiyang palace construction, wide, in the city, for small, west across the city as a fly in the palace pavilion, JianZhang palace, compose chariot servings. Chariot for cabinet, can take a chariot."

\section{Conclusion}

Through history, we see the garden bridge also experienced three important period of transition, the field of natural interest from pre-qin to han development to the "garden" out of landscape architecture; To the northern and southern dynasties to tang dynasty, with the landscape of the emergence of bud of miniaturization, private garden, was shown in the tomb murals and stone garden bridge, bridge formation as the garden; Finally, with the tang dynasty to song dynasty period, China's garden art gradually mature period, development to the Ming and qing dynasties, the crest of garden art period in our country. Landscape art and more and more exquisite technology, perfect; Especially in mid late jiangnan area of the bureaucratic landlords garden prosperity, the middle period of qing dynasty, yangzhou, the rise of the jiangnan private gardens. Contributed to the rich and colorful of jiangnan private garden now, thus formed the garden important architectural form "garden bridge" mature period. With three historical period of transition, the garden bridge with the materials and functions has changed significantly, from the initial emphasis on functional road connections, development as the function and appreciate the important architectural form of private gardens, and finally became a predominantly appreciate "architectural art". Until now, the landscape architecture art "still keep in landscape design and full of exuberant vitality.

\section{Acknowledgments}

This work was financially supported by: graduate student research innovation project (CXZZ12_0800); Jiangsu university advantage disciplines construction engineering projects (PAPD).

\section{References}

[1] (Ming) into the, Chen Zhi annotations, embodied annotations (M), Beijing: China building industry press, $1988(05)$

[2] (tang) Liu Guangwei that Cao Lindi collation, remember wu (M), nanjing: jiangsu ancient books publishing house, 1999

[3] Fan Chengda writes, "Wu Jun volunteers", the southern song dynasty at pingkiang government record, jiangsu ancient books publishing house, 1999:214

[4] Fu Xinian, ancient Chinese architecture (M) the second volume, jin, northern and southern dynasties, sui tang five dynasties building, Beijing: China building industry press, 2001 (12): 150 